Témoigner Témoigner. Entre histoire et mémoire

Getuigen Revue pluridisciplinaire de la Fondation Auschwitz

$121 \mid 2015$

Violences radicales en scène

\title{
Culture de la mémoire ou anthropologie de la vérité ?
}

\section{Catherine Coquio}

\section{Q OpenEdition}

1 Journals

\section{Édition électronique}

URL : https://journals.openedition.org/temoigner/3138

DOI : 10.4000/temoigner.3138

ISSN : 2506-6390

Éditeur :

Éditions du Centre d'études et de documentation Mémoire d'Auschwitz, Éditions Kimé

\section{Édition imprimée}

Date de publication : 1 octobre 2015

Pagination : $22-23$

ISSN : 2031-4183

\section{Référence électronique}

Catherine Coquio, «Culture de la mémoire ou anthropologie de la vérité ?», Témoigner. Entre histoire et mémoire [En ligne], 121 | 2015, mis en ligne le 01 octobre 2016, consulté le 04 février 2022. URL http://journals.openedition.org/temoigner/3138 ; DOI : https://doi.org/10.4000/temoigner.3138

Tous droits réservés 


\section{CULTURE DE LA MEMOIRE OU ANTHROPOLOGIE DE LA VERITÉ ?}

\author{
LIVRE Entretien avec Catherine Coquio \\ à l'occasion de la sortie de son livre \\ Le Mal de vérité ou l'utopie de la mémoire'.
}

Témoigner entre histoire et mémoire : Votre livre a été publié en même temps que La Littérature en suspens. Les deux ouvrages prennent-ils place dans un même projet?

Catherine Coquio : La Littérature en suspens est issue d'un travail qui a débuté dans les années 1990, sur des textes de témoins de la Shoah et des camps nazis. Le Mal de vérité est issu d'une sensation de malaise plus récente, qui touche à la « culture de la mémoire », ce phénomène aussi bien institutionnel que pédagogique, avec des effets de médiatisation, d'idéologisation, mais aussi de dépolitisation. Notre hantise de la transmission est devenue religion, presque mission : j'ai été frappée par les relents chré-

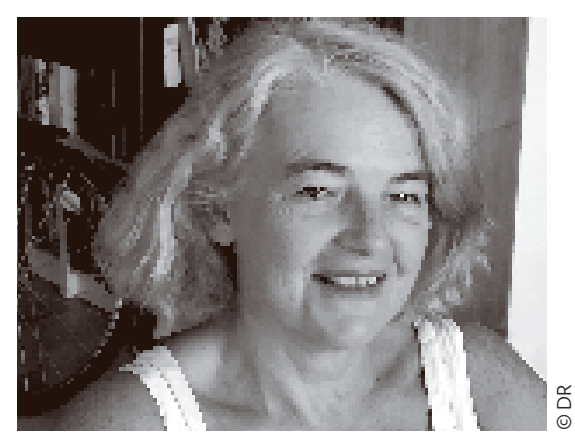

par un transfert de sacralité. C'est sur ces questions du sacré à l'œuvre dans la mémoire et la vérité, que j’ai voulu travailler. Tandis que dans La Littérature en suspens, j’étudie la créativité poétique des témoins et je tente de recueillir la libre pensée que leurs textes recèlent. On ne peut pas remplacer ces textes, souvent très iconoclastes, au nom de la « loi du relais », par une autre littérature générationnelle, inévitablement plus conforme et dénuée de cette puissance critique, sans une perte de sens du mot mémoire. Cette perte est un des objets du Mal de vérité. Ce sont donc des ouvrages complémentaires.

"Le mal de vérité est un mal particulier, né d'un mensonge politique particulier ", écrivez-vous. De ce mal, issu de la destruction du réel, naîtrait une "vérité sans autorité ».

C.C. : La vérité de tels événements peine à s'établir, à se fonder. L'obsession mémorielle provient du refus d'oublier les disparus, mais aussi de l'angoisse d'une définitive destruction de la vérité. Et cela renvoie à ce qui a eu lieu au présent: l'effondrement de l'autorité du réel et la perte totale de sens qui s'ensuit. Ce mal n’a rien de métaphysique, au contraire il provient de l'abolition de la «mort métaphysique» dont parle Améry. Il faut un mensonge total, pour reprendre Arendt, pour parvenir à détruire un peuple ou une société. Cette innovation politique crée un besoin de revenir sur les preuves, mais aussi un éclatement de la vérité, dont on ressent les conséquences dans nos régimes démocratiques actuels. Le mal de vérité, qui explique le violent besoin de témoigner, ne va pas tiens et apostoliques de notre morale du «passage de témoin », sorte de nouvel évangile mémoriel, et je me suis demandé pourquoi cette rechristianisation du témoin semi-consciente : quête d'une éthique de l'après, mais aussi désir de re-sublimer la littérature

(1) Catherine Coquio, Le Mal de vérité ou l'utopie de la mémoire, Paris, Armand Colin, «Le temps des idées », 2015, 317 p. Catherine Coquio est professeur de littérature comparée à l'Université Denis-Diderot. Elle a créé en 1997 l'Association internationale de recherches sur les crimes contre l'humanité et les génocides, qu'elle a présidée jusqu'en 2008. Elle est l'auteure, entre autres, de Rwanda. Le réel et les récits (2004), L’Art contre l'art (2006), L'Enfant et le génocide (avec Aurélia Kalisky, 2007). sans une crise inédite de la vérité. De là toutes les disputes entre les disciplines et les savoirs, d'où aussi le désir d'historiographie sans fin. Nous sommes héritiers de ce mal en vivant dans un certain chaos, à la fois épistémologique et politique. Les disputes autour des lois mémorielles sont un symptôme typique de cet éclatement. Le mal de vérité n'est pas le vieil amour de la vérité, ni la volonté de savoir occidentale, et la crise de la vérité ne se ramène pas à l'ancestrale division de la vérité. Ce problème réclame une autre approche philosophique, une anthropologie historique de la vérité : pour penser la vérité il faut écouter ceux qui 
l'ont pensée à travers leur mal, ce que je tente avec Kertész, Chalamov, Margolin, Celan, Andonian... J'essaie de lire ces littératures en traversant l'écran culturel, tout en radiographiant notre culture de la mémoire : une sorte d'herméneutique.

Ce mal semble avant tout celui de l'Europe occidentale. Que faire alors des mémoires instrumentalisées dans d'autres parties du monde?

C.C. : Évidemment, il y a des endroits du monde où l'appel à la mémoire reste noué à la restitution du réel, où le témoignage et le travail historiographique impliquent un engagement politique fort et dangereux. Mais une crise généralisée a lieu, d'abord parce que le mal de vérité est un phénomène anthropologique partagé, ensuite du fait de la surchauffe et de la mondialisation du langage mémoriel. Cette crise prend des formes diverses : j’évoque le Rwanda, le Cambodge, l'Arménie, l'ex-Yougoslavie et le Proche Orient, mais j'interroge en effet surtout notre nihilisme postmémoriel, qui nous prive d'un rapport à l'avenir. Dans la pédagogie actuelle, par exemple, je vois des effets de déraillement dangereux : notre angoisse historique nous fait éduquer les enfants dans la pensée de l'Histoire comme série de massacres. Or notre histoire s'est aussi nourrie d'une série d'espoirs qui, même s'ils ont été déçus, nous ont fait agir et nous ont instruits. C'est ce désir de comprendre et d'agir qu'il faudrait tenter de transmettre.

Vous vous en prenez à cette « religion civique » que serait devenue la Mémoire. Comment être aussi intransigeante quand cette mémoire, avec et malgré tout ce qu'on lui reproche, est aussi une réponse aux aléas et aux errements de la reconnaissance des quarante années après la guerre?

C.C. : J'ai moi-même beaucoup bataillé pour les reconnaissances, qui sont des réponses vitales aux violentes attaques contre la mémoire et la vérité. Les « abus de mémoire » sont des effets obligés du « mal de vérité ». Mais il y a une étape autocritique à franchir, des points aveugles à affronter, une autre manière de lire, une réflexion philosophique à initier aussi. Le problème ne vient pas des « acteurs de la mémoire », qu'ils soient individuels ou institutionnels (quand la mémoire devient culture, tous en deviennent les acteurs !), mais des manipulations politiques et de l'inertie médiatique, de ce catéchisme du mal absolu et du devoir de mémoire qui déréalise tout. Pour ma part, j'essaie d'interpréter les éléments de foi et d'espérance enfouis dans ces constructions mémorielles. Qu'estce qui fait que l'on croit à ce point au témoignage, à la catharsis? N’y a-t-il pas là un «principe espérance » à l'envers ? Or toute mythologie comporte un donné aliénant mais aussi un potentiel émancipateur. C'est pourquoi cette culture sacralisée doit être sécularisée.

La « (re)christianisation de la mémoire », est-ce un phénomène européen?

C.C. : Il y a, avec les replis identitaires, un retour du religieux qui excède ce que nous vivons dans notre culture mémorielle, et quile menace, aussi: le salafisme détruit toute forme d'histoire, y compris musulmane. Cette rechristianisation par le témoin, liée au désir d'universaliser la Shoah et d'être présent à tous les maux du monde, en est sans doute la forme occidentale actuelle.

Vous faites intervenir l'actualité (Charlie Hebdo, la Syrie...). Ainsi, les violences dont on est spectateurs bousculeraient les effets bénéfiques attendus de la mémoire sur le vivre ensemble. Mais n'est-ce pas trop demander à la mémoire?

C.C. : Si. Mais on ne peut pas faire de la mémoire - et pas seulement de la Shoah - un objet qui aurait atteint sa vitesse de croisière sur les plans académique ou culturel, sans s'affronter aux enjeux politiques d'aujourd'hui. Ceux-ci nous mettent en face d'autres formes de pathologie mémorielle, notamment dans le monde arabe, qui a ses propres plaies, ses propres « maux de vérité ». Pour moi, l'enjeu fondamental des recherches sur la mémoire aujourd'hui, c'est d'arriver à faire dialoguer ces mémoires déchirées entre l'Orient, l'Afrique et l'Occident. Quelle position prendre face à l'actuel drame des réfugiés, et comment ne pas perdre pied face à l'énorme problème du XXI ${ }^{\mathrm{e}}$ siècle que seront les migrations massives?

Mais qu'est-ce que cela a à voir avec le travail de mémoire?

C.C. : Ily a en effet un hiatus : ces problèmes relèvent d'autre chose que de consciences non partagées du passé. Mais on gagnerait à réfléchir avec précision sur les causes profondes des déchirements d'humanité actuels. Ces migrations vont faire histoire en entraînant d'autres violences, donc d'autres guerres de mémoires et litiges sans fin. Il ne faut pas nous laisser surprendre. 